\title{
Empreendedorismo informal em balneários marítimos: o caso da atividade comercial turística de vendedores ambulantes de Pontal do Paraná - Paraná - Brasil
}

\author{
Informal entrepreneurship in coastal cities: the case of the tourist commercial activity of street \\ vendors of Pontal do Paraná - Paraná - Brazil
}

\author{
Raquel dos Santos Vieira ${ }^{1}$ \\ Marcelo Chemin ${ }^{2}$
}

\begin{abstract}
Resumo
$\mathrm{O}$ artigo analisa o empreendedorismo informal relativo à atividade comercial turística dos vendedores ambulantes do município balneário de Pontal do Paraná - PR - Brasil. Trata-se de atividade economicamente expressiva por ser praticada por aproximadamente $2,5 \%$ da população fixa total do referido município (IBGE, 2018). Com abordagem qualitativa e caráter exploratório, a pesquisa foi delineada como estudo de caso e utilizou como estratégias de investigação: pesquisa documental, entrevistas não estruturadas e semiestruturadas e aplicação de questionários. Os resultados apontaram que a atividade está organizada a partir da Associação dos Vendedores Ambulantes de Pontal do Paraná - AVAPAR e da Prefeitura Municipal. Os vendedores ambulantes apresentaram perfil empreendedor, informaram apreço pela função exercida, desinteresse por outro emprego e pelo vínculo formal da carteira assinada, trabalham em cooperação e buscam realizar parcerias entre si.
\end{abstract}

Palavras-chave: Empreendedorismo informal. Turismo em balneários. Vendedores ambulantes. Pontal do Paraná (PR).

\begin{abstract}
The article analyzes the informal entrepreneurship related to the tourist commercial activity of street vendors of Pontal do Paraná, a coastal municipality in the State of Paraná, Brazil. This is an economically significant activity because about the $2.5 \%$ of the town's total population perform it (IBGE, 2018). The research has a qualitative approach and an exploratory nature. It was designed as a case study and uses, as investigation strategies, documental research, non-structured and semistructured interviews, and questionnaires application. The results show that the activity is organized from the Association of the Street Vendors of Pontal do Paraná (AVAPAR) and the municipal administration. The street vendors have an entrepreneurial profile, showing appreciation for their work, lack of interest for another job or formal employment as regular employees. They work in cooperation and seek to build partnerships among each other.

Keywords: Informal entrepreneurship. Tourism in coastal cities. Street vendors. Pontal do Paraná (PR).

\footnotetext{
${ }^{1}$ Bacharela em Gestão e Empreendedorismo pela Universidade Federal do Paraná (UFPR). Doutoranda em Meio Ambiente e Desenvolvimento (UFPR).E-mail: raquelsantosufpr@gmail.com

${ }^{2}$ Doutor em Geografia (UFPR). Professor do Curso de Gestão de Turismo e do Programa de Pós-Graduação em Turismo (UFPR). E-mail: marcelochemin@ufpr.br
} 


\section{Introdução}

Territórios costeiros habitualmente são pontuados por destinos turísticos, muitos dos quais classificados como resorts, cidades balneárias ou simplesmente balneários. Trata-se de uma realidade comum em diferentes países, notadamente os situados na América Central, Caribe, Europa e América Latina. Parte da dinâmica socioeconômica e turística dessas localidades apresenta como uma de suas principais características a sazonalidade de visitação, sobretudo para destinos cujo segmento de oferta está direcionado ao turismo de lazer ou sol e praia (LOHMANN; PANOSSO NETTO, 2012).

No litoral do Paraná, localidade definida e reconhecida como tradicional "região turística" (SAMPAIO, 2006b), o turismo de sol e praia é considerado significativo para o conjunto de atividades econômicas (IPARDES/BDE, 2011). A região, cuja população total estimada para o ano de 2018 é de aproximadamente 289 mil habitantes (IBGE, 2019), é conformada por sete municípios, dos quais três são balneários marítimos - Guaratuba, Matinhos e Pontal do Paraná, que experimentam efeitos ainda pouco estudados decorrentes da sazonalidade. A sazonalidade pode ser entendida como flutuações resultantes do aumento e da redução da demanda pelo mercado e pode ser definida, ainda, como um fenômeno que acontece em alguns períodos e em outros não (MOTA, 2001; CASTELLI, 1986).

É nesse contexto que se insere Pontal do Paraná, desmembrado de Paranaguá em 1997 (PIERRI, 2003; PIERRI et al., 2006), razão pela qual é o município mais jovem desse litoral. O município tem sua economia baseada em atividades relacionadas ao turismo, no período de temporada de verão, de dezembro a fevereiro, que emprega boa parte da população residente e atrai pessoas de outras regiões. No período de baixa temporada, de março a novembro, a economia é caracterizada pela pesca e, esporadicamente, pela realização de pequenos e médios eventos. (IPARDES/BDE, 2011). No que se refere à sazonalidade, durante os meses de temporada de verão, devido ao aumento do número de visitantes que se deslocam dos seus municípios de origem para o litoral paranaense, são criados em Pontal do Paraná empreendimentos no mercado informal para atendimento aos turistas.

A informalidade, segundo Dedecca (2007), compreende todos os trabalhadores sem proteção trabalhista e social ou que não contribuem para a previdência social, tanto do setor formal quanto do informal. Para o autor, as relações de trabalho informais são intrínsecas ao desenvolvimento do capitalismo das últimas décadas. Nesse sentido, Machado da Silva (1971), ao estudar os mercados metropolitanos de trabalho manual do Rio de Janeiro, constatou que o mercado 
informal, assim como o formal, encontrava-se fortemente institucionalizado, trazendo a discussão para outros espaços também informais.

Cacciamali (2000) associa dois fenômenos à informalidade: um associado à reorganização do trabalho assalariado, devido ao aumento do número de empregos assalariados sem registro em carteira de trabalho, e outro referente às diferentes formas de autoemprego, que representam estratégias de sobrevivência, como o trabalho por conta própria ou em microempresas.

Os setores formal e informal, segundo Cacciamali (1983) e Soares (2008), são interdependentes, sendo que o setor informal é subordinado ao setor formal. Assim, os autores argumentam que tais setores não podem ser tratados como uma visão dual da realidade, pois correspondem a relações de produção não isoladas. A interdependência dos setores formal e informal apontada pelos autores é observada em Pontal do Paraná, com a criação de empreendimentos informais e, até mesmo, temporários na temporada de verão para atendimento aos turistas e veranistas.

Neste estudo, um empreendimento é entendido como um processo de criar algo novo, dedicando tempo e esforço necessário, assumindo riscos e recebendo as recompensas (HISRICH; PETERS, 2004). Parte desses empreendimentos informais atua na área de vendas, comercializando produtos como alimentos, bebidas e souvenires, e dentre estes estão os vendedores ambulantes, que costumeiramente não possuem um ponto fixo de trabalho (SULZBACH; DENARDIN; FELISBINO, 2012).

O comércio ambulante em Pontal do Paraná constitui um componente relevante para a economia do município, pois em 2016 os registros da municipalidade indicaram o total de 600 vendedores ambulantes, excedendo o número de vagas anualmente oferecidas pela legislação municipal (551), como revelou a pesquisa que deu origem a esta comunicação, número considerável na medida em que o pessoal ocupado para o ano de 2016 compreendia 7.561 (IBGE, 2016).

Ao considerar que tal atividade comercial passa por vezes despercebida aos olhares comuns e de políticas de qualificação, apoio e incentivo, a pesquisa aqui comunicada foi construída a partir do seguinte questionamento: como se caracteriza o empreendedorismo informal relativo à atividade comercial turística dos vendedores ambulantes do município balneário de Pontal do Paraná - Paraná - Brasil?

Definiu-se como objetivo geral: analisar o empreendedorismo informal relativo à atividade comercial turística dos vendedores ambulantes do município balneário de Pontal do Paraná - PR Brasil. Adicionalmente, figuraram como objetivos específicos: 1. Identificar as formas de organização da atividade comercial turística dos vendedores ambulantes; 2. Identificar 
características de perfil socioeconômico e de comportamento empreendedor de vendedores ambulantes; e 3. Analisar aspectos do processo de criação de empreendimentos informais de vendedores ambulantes.

Para alcançar os objetivos propostos, adotou-se abordagem qualitativa e caráter exploratório. A pesquisa foi delineada como estudo de caso e utilizaram-se, como estratégias de investigação, pesquisa documental, entrevistas não estruturadas e semiestruturadas e aplicação de questionários.

\section{Material e Métodos}

A abordagem qualitativa foi escolhida para a pesquisa por ser considerada "um meio para explorar e para entender o significado que os indivíduos ou os grupos atribuem a um problema social ou humano" (CRESWELL, 2010, p. 26).

Devido à pretensão de abordar um tema não totalmente dominado pelo pesquisador e à finalidade de aprofundar conhecimentos, a pesquisa se caracteriza, quanto aos objetivos, como exploratória (GIL, 2002).

O estudo de caso foi escolhido como método por possibilitar a investigação de "um fenômeno contemporâneo em profundidade e em seu contexto de vida real, especialmente quando os limites entre o fenômeno e o contexto não são claramente evidentes" (YIN, 2010, p. 39).

Quanto às estratégias de investigação utilizadas na pesquisa, estas diferiram para cada um dos objetivos específicos. Para a identificação das formas de organização da atividade comercial turística dos vendedores ambulantes, foram utilizadas a pesquisa documental, na Internet, site institucional da Prefeitura Municipal de Pontal do Paraná, páginas da rede social Facebook relacionadas ao município, estatuto da Associação dos Vendedores Ambulantes de Pontal do Paraná - AVAPAR e lei que regulamenta o comércio ambulante no município. Também foram realizadas entrevistas informais com o presidente, o vice-presidente e a secretária da AVAPAR; o chefe de Departamento de Cadastro e Tributação da Secretaria Municipal de Finanças de Pontal do Paraná, responsável pela emissão das licenças para trabalhar como vendedor ambulante no comércio turístico do município; e fiscais do Departamento de Vigilância Sanitária e Epidemiológica do Município de Pontal do Paraná, responsáveis pela realização da palestra sobre Vigilância à Saúde aos vendedores ambulantes, pela vistoria dos carrinhos dos vendedores ambulantes e pela fiscalização dos vendedores ambulantes quando da atividade comercial na praia. As entrevistas realizadas foram transcritas e analisadas utilizando-se a análise de conteúdo (BARDIN, 2010). 
Para identificação de características de perfil socioeconômico e de comportamento empreendedor de vendedores ambulantes, fez-se uso de questionário adaptado de Silva (1999) e o questionário baseado na teoria das características comportamentais empreendedoras de David Clarence McClelland apud Bartel (2010). A aplicação dos questionários não buscou generalizar os dados coletados; a intenção está ligada ao conjunto de procedimentos que intencionam entender o contexto estudado e os sujeitos da pesquisa, já que o tema é pouco contemplado e o público-alvo apresenta especificidades de rotina laboral, o que dificulta contatos mais alongados e frequentes.

Os vendedores ambulantes foram convidados a responder os questionários na ocasião do treinamento obrigatório em Vigilância à Saúde realizado pelo Departamento Municipal de Vigilância Sanitária e Epidemiológica de Pontal do Paraná na sede da AVAPAR, no qual participaram 80 vendedores ambulantes. Foram entregues, grampeados, 80 questionários de perfil socioeconômico e 80 de comportamento empreendedor. O retorno de questionários respondidos foi de 27 de perfil socioeconômico e 25 de comportamento empreendedor. No entanto, 5 questionários de comportamento empreendedor tiveram vários itens não respondidos, consequentemente, foram invalidados. Assim, foram validados e analisados 27 questionários de perfil socioeconômico e 20 de comportamento empreendedor.

Para análise do perfil socioeconômico, os dados coletados foram tabulados e analisados com o auxílio do software Microsoft Office Excel. O questionário utilizado para coleta de dados sobre o perfil empreendedor é composto de 55 (cinquenta e cinco) afirmações relacionadas às dez características comportamentais (busca de oportunidades e iniciativas; persistência; correr riscos calculados; exigência de qualidade; comprometimento; busca de informações; estabelecimento de metas; planejamento e monitoramento sistemático; persuasão e rede de contatos; e independência e autoconfiança) que integram os conjuntos de Realização, Planejamento e Poder (MCCLELLAND ${ }^{3}$, 1972 in BARTEL, 2010).

Cada afirmação podia ser respondida a partir de uma escala de 1 a 5 , devendo os respondentes escolher uma variante de resposta, sendo 1 = nunca; 2 = raras vezes; 3 = algumas vezes; 4 = usualmente e $5=$ sempre. As pontuações atribuídas pelos respondentes foram transferidas para um formulário específico para calcular a pontuação de cada característica e dos conjuntos de características.

No que se refere à análise do processo de criação de empreendimentos informais de vendedores ambulantes, foram conduzidas entrevistas semiestruturadas, baseadas em Sarasvathy,

3 MCCLELLAND, D. C. A sociedade competitiva: realização e progresso social. Rio de Janeiro: Expressão e Cultura, 1972. 
adaptado de Pelogio (2011). Foram realizadas seis entrevistas, três face a face, com média de uma hora de duração, e as outras três por telefone, com duração média de trinta minutos. As entrevistas foram transcritas e analisadas com base na análise de conteúdo, assim como as entrevistas realizadas para responder o primeiro objetivo específico do estudo.

As entrevistas realizadas para os objetivos específicos 1 e 3 foram analisadas seguindo as etapas orientadas por Bardin (2010). Inicialmente, foram transcritas na íntegra, em seguida foram sistematizadas. Um primeiro grupo de sistematização aglutinou informações sobre cadastros, legislação municipal, treinamentos obrigatórios, vistorias e fiscalização. Outro grupo atendeu informações sobre perfil, atuação e rede, por exemplo: “Quem são?”, “O que eles conhecem?”, “Quem eles conhecem?”, clareza de objetivos iniciais, tolerância às perdas e investimentos iniciais e alavancagem sobre contingências - surpresas e dificuldades iniciais.

A pesquisa de campo foi realizada no período entre dezembro de 2014 e março de 2016 e se deu em quatro etapas: a primeira consistiu em entrevistas com pessoas da AVAPAR. Na segunda etapa foram aplicados os questionários referentes às características socioeconômicas e de comportamento empreendedor dos vendedores ambulantes. A terceira etapa consistiu em entrevista com membros da Prefeitura Municipal. Na quarta etapa foram realizadas as entrevistas sobre os aspectos do processo de criação dos empreendimentos dos vendedores ambulantes.

\section{Apresentação dos Resultados e Análises}

Os resultados da investigação e as respectivas análises articulam os três tópicos seguintes: o primeiro sobre as formas de organização da atividade comercial turística dos vendedores ambulantes de Pontal do Paraná, o segundo sobre as características de perfil socioeconômico e de comportamento empreendedor e o terceiro sobre o processo de criação de empreendimentos dos vendedores ambulantes.

\section{Formas de organização da atividade comercial turística dos vendedores ambulantes de Pontal do Paraná}

Em Pontal do Paraná, a atividade comercial turística dos vendedores ambulantes está organizada a partir de duas instituições: a AVAPAR e a Prefeitura Municipal, apresentando-se de forma institucionalizada, conforme indica Machado da Silva (1971).

A AVAPAR é a instituição responsável pela realização do cadastro dos candidatos a vendedores ambulantes, bem como a renovação dos cadastros dos ambulantes antigos mediante 
recolhimento de taxa. Após a renovação e realização dos novos cadastros, os candidatos devem participar de momento de aperfeiçoamento e qualificação, mediante palestra sobre Vigilância à Saúde, realizada pelo Departamento Municipal de Vigilância Sanitária e Epidemiológica na sede da AVAPAR.

Os produtos comercializados pelos vendedores ambulantes e o setor de exercício da atividade para cada vendedor são definidos no momento do cadastro a partir das vagas disponíveis na Legislação Municipal n 621, de 18 de novembro de 2005, que "Dispõe sobre o exercício de comércio ambulante e de comércio ou prestação de serviço eventual, no Município de Pontal do Paraná, durante o período considerado “temporada de verão"” (PONTAL DO PARANÁ, 2005).

Os cadastros realizados pela AVAPAR são encaminhados para a Prefeitura Municipal de Pontal do Paraná que, a partir do Departamento de Cadastro e Tributação, e seguindo a Lei no 621, de 18 de novembro de 2005, convoca os candidatos classificados para desenvolver a atividade, dentro do número de 551 vagas definidas na legislação municipal. Os candidatos passam então por vistoria de carrinhos e equipamentos, realizada pelo Departamento Municipal de Vigilância Sanitária e Epidemiológica, pautada no Código de Saúde do Paraná. Os aprovados recebem um selo de vistoria, que corresponde à chancela da municipalidade para o exercício da função por um determinado tempo.

Após a aprovação na vistoria realizada pelo Departamento de Vigilância Sanitária e Epidemiológica, os candidatos apresentam o comprovante de recolhimento da taxa municipal, no Departamento de Cadastro e Tributação, para que possam ser expedidas as licenças.

Juntamente com as carteirinhas de identificação, os classificados recebem do Departamento Municipal de Cadastro e Tributação os uniformes, medida de apoio ao desenvolvimento das atividades como vendedores ambulantes.

Durante o período de temporada de verão, o Departamento Municipal de Vigilância Sanitária e Epidemiológica realiza fiscalização dos carrinhos e equipamentos dos vendedores ambulantes, notadamente em atividade na areia da praia.

A organização da atividade comercial turística em Pontal do Paraná é consistente e se alinha à terceira corrente de interpretação sobre informalidade defendida por Cacciamali (1983) e Soares (2008), que afirmam que a atividade informal não acontece subordinada ao capitalismo, mas como parte dele, inserida na produção moderna, constatando-se, assim, a funcionalidade da informalidade como elemento positivo.

Essa corrente de interpretação afirma ainda que a atividade informal se instala em espaços econômicos não ocupados pelas atividades formais, como é o caso dos vendedores ambulantes, que 
recebem uma licença específica para desenvolver essa atividade que ocorre há muito tempo no município, sendo que todos os anos os praticantes se preparam e esperam para desenvolver tal atividade (CACCIAMALI, 1983; SOARES, 2008).

A terceira corrente de interpretação defendida por Cacciamali (1983) e Soares (2008) afirma também que os setores formal e informal ocorrem paralelamente, como parte do capitalismo, em que a atividade informal se desloca de um mercado para outro conforme a necessidade do cenário econômico. Nesse caso, o cenário econômico da atividade dos vendedores ambulantes se altera com a chegada do período de temporada de verão.

O número de pessoas que desenvolve atividades como vendedores ambulantes no município de Pontal do Paraná (551) compreende aproximadamente 2,5\% da população desse município, segundo o IBGE (2018), demonstrando a expressividade dessa atividade de empreendedorismo informal para o município, mesmo sendo sazonal.

\section{Características de perfil socioeconômico e de comportamento empreendedor de vendedores ambulantes de Pontal do Paraná}

Foram validados e analisados 27 questionários de perfil socioeconômico e 20 questionários de características de comportamento empreendedor.

Responderam ao questionário de perfil socioeconômico um total de 10 homens e 17 mulheres, com idades entre 18 e 80 anos, sendo que 18 respondentes apresentaram idades no intervalo 31 a 60 anos, representando expressividade entre os entrevistados. Quanto ao estado civil, a maioria dos respondentes (13) declararam estar casados, seguidos dos que declararam estar solteiros (5). A maioria dos respondentes (22) afirmaram ter filhos.

Quanto às cidades de origem, coube destaque à Curitiba, indicada por 7 respondentes. Paranaguá foi indicado por 3. Colombo, localizado na região metropolitana de Curitiba, foi indicado por 2. Os seguintes municípios e estados foram indicados por cada um dos demais respondentes: Minas Gerais, Rondon/PR, Pato Branco/PR, Lisboa/Portugal, Porto Alegre/RS, Rio do Sul/SC, Lajinha/MG, Faxinal do Céu/PR, Minador do Negrão/AL, Morretes/PR, Três Passos/RS, Alagoas, Jaboti/PR, Ibaiti/PR. Dos respondentes, 17 residem em Pontal do Paraná por um período de tempo de até $10(\mathrm{dez})$ anos.

Referente à escolaridade, 11 vendedores ambulantes respondentes concluíram o Ensino Médio. De outro modo, 7 afirmaram ter estudado até a conclusão do $1^{\circ}$ ciclo do Ensino Básico (4º ano) e 1 declarou não ter estudado. 
As razões apontadas como motivadoras para trabalhar como vendedor ambulante foram "independência", "autonomia", "liberdade" e "dificuldade de encontrar emprego" (8 respondentes cada), seguida por "ganhar mais" (6 respondentes). Esses dados nos remetem ao que aponta Cruz (2014), que as pessoas também empreendem por oportunidade ou necessidade, assim como no empreendedorismo formal (GEM, 2013). A "dificuldade para encontrar emprego" representa uma necessidade, enquanto "independência", "autonomia" e "liberdade" caracterizam oportunidades.

Quatorze dos respondentes indicaram trabalhar como vendedor ambulante há até cinco anos. Todos os respondentes indicaram já ter trabalhado em outra atividade, sendo que 23 já tiveram vínculo com carteira assinada.

Um total de 18 respondentes indicaram ter na atividade de vendedor ambulante sua única fonte de renda. Contudo, seis respondentes indicaram estar buscando outra ocupação e 19 pesquisados indicaram não buscar outro emprego.

A maioria dos respondentes (24) costuma trabalhar principalmente no período de temporada de verão, com uma jornada de trabalho entre oito e dez horas (18 entrevistados), sendo que a maioria (22) trabalha por conta própria. Dentre os entrevistados, 7 afirmaram contribuir com a previdência social de maneira autônoma.

Os vendedores ambulantes são caracterizados como trabalhadores por conta própria, que empregam a si mesmos (CACCIAMALI, 1983; SOARES, 2008) e trabalham, em sua maioria, no período de temporada de verão e alguns finais de semana e feriados durante o ano, quando há fluxo de turistas no município, caracterizando tal atividade como sazonal.

Considera-se que a informalidade tende a ser um elemento de geração de empreendedores, como apontado por Cruz (2014), visto que 22 dos 27 respondentes do questionário sobre perfil socioeconômico trabalham por conta própria.

Oito entrevistados indicaram que gostariam de mudar para um emprego com carteira assinada, sendo 5 por segurança financeira. Por outro lado, 14 pesquisados não gostariam de mudar para um emprego com carteira assinada pelos motivos: "salário baixo", "gostar de ter negócio próprio" e "gostar de ser vendedor ambulante".

Quando questionados sobre o local de aquisição dos produtos, a maioria (18) indicou adquirir seus produtos para comercialização no município onde residem, Pontal do Paraná. Referente à forma de obtenção dos produtos, 21 indicaram obter a partir de recursos financeiros próprios.

No que se refere às características de comportamento empreendedor, as médias obtidas foram consideradas altas. As características comportamentais que obtiveram as maiores médias 
foram: (a) Independência e autoconfiança, (b) Estabelecimento de Metas e (c) Comprometimento. Essas características demonstram que os vendedores ambulantes: (a) confiam na própria capacidade e se mantêm confiantes diante de situações desanimadoras, (b) estabelecem metas mensuráveis, claras, específicas e desafiadoras e que, ao mesmo tempo, tenham significado pessoal e (c) que para concluir uma tarefa se esforçam e colaboram com os demais, bem como buscam manter os clientes satisfeitos, considerando que a atividade reflete uma relação de longo prazo e não apenas o lucro no curto prazo (BARTEL, 2010).

A diferença entre a média do conjunto de Planejamento, que apresentou a maior pontuação, e do conjunto de Poder, que apresentou a menor pontuação, foi de menos de um ponto, não sendo considerada como significativa.

Indivíduos que apresentam as características do conjunto de realização, segundo McClelland (1972 in BARTEL, 2010), dedicam mais tempo a tarefas desafiadoras e preferem depender de habilidades próprias para alcançar resultados. Tal necessidade envolve aceitação das habilidades e tendência a tomar iniciativa e obter melhor qualidade, produtividade, crescimento e lucratividade, em que os indivíduos se colocam em situações altamente competitivas com metas realistas e executáveis

O conjunto de planejamento representa que os indivíduos apresentam capacidade de planejamento nas soluções criativas, em planos empresariais e operacionais, metas, objetivos, informações e feedbacks, reforçando as características do indivíduo em: estabelecer laços de amizades, ser aceito, fazer parte de grandes grupos sociais e preocupar-se com o rompimento de relações interpessoais positivas (MCCLELLAND, 1972 in BARTEL, 2010)

Os indivíduos que apresentam as características comportamentais do conjunto de poder, de acordo com McClelland (1972 in BARTEL, 2010), são aqueles que executam ações poderosas, despertam reações emocionais nas pessoas e preocupam-se com a reputação, status e posição social com os objetivos de melhorar a capacidade individual, encontrar cooperação necessária, influenciar e negociar, buscando estratégias eficientes e cooperação através de uma rede de contatos.

Essas constatações são positivas no que se refere à possibilidade de desenvolver suas atividades de maneira a atrair mais turistas, visto que os aspectos comportamentais do empreendedor, assim como seus valores pessoais, são diretamente refletidos no empreendimento.

\section{Processo de criação de empreendimentos dos vendedores ambulantes de Pontal do Paraná}

Foram entrevistados 6 vendedores ambulantes sobre o processo de criação de empreendimentos. Três entrevistas foram realizadas face a face, com duração média de uma hora, e 
três entrevistas realizadas por telefone, com duração média de 30 minutos. Dos empreendedores entrevistados, 4 são do sexo masculino e 2 do sexo feminino, com idades entre 38 e 62 anos. Cinco são casados e têm filhos e 1 é solteiro e não tem filhos. Três estudaram Ensino Médio Completo, 2 Ensino Médio Incompleto e 1, $1^{\circ}$ ciclo do Ensino Básico Incompleto. Cinco dos informantes são naturais de cidades do Paraná. Os informantes chegaram ao município de Pontal do Paraná nos anos: 1997, 1999, 2007, 2013 e dois em 2001. Os balneários de residência dos entrevistados são: Ipanema, Praia de Leste, Shangri-lá e Pontal do Sul.

Os motivos indicados pelos entrevistados que os levaram a se mudar para Pontal do Paraná foram: "qualidade de vida", "clima", "não ter que pagar aluguel”, "tranquilidade pra criar os filhos", "falência de empresa familiar na cidade de origem", "morar com a irmã após o falecimento da mãe", "casamento" e "recomendações médicas".

Os pais dos entrevistados tinham as seguintes ocupações: garçom, agricultores e posteriormente, empreendedor familiar e pescadores. Dentre as mães dos entrevistados, predomina a ocupação de dona do lar. Dois dos entrevistados afirmaram ter casos de empreendedores na família.

As experiências profissionais indicadas pelos empreendedores foram distintas, como: farmácia, garçom, trabalho no exército, pedreiro, jardineiro, encanador, reparos em geral, auxiliar de serviços gerais, cozinheira e adestrador de cães, sendo que 1 dos entrevistados já tinha experiência como vendedor ambulante em outra região do país.

Quanto aos treinamentos, cursos e capacitações, 3 informantes mencionaram ter realizado os seguintes cursos: aproveitamento do resíduo do coco, panificação, capelania evangélica e atendimento ao turista; cozinheira e armador de ferragens, além do treinamento de Vigilância à Saúde, realizado obrigatoriamente para o exercício do comércio ambulante.

Noronha (2003) assinala que as redes sociais são essenciais para a realização das atividades informais. Essa afirmação pôde ser constatada a partir dos resultados obtidos da entrevista sobre o processo de criação de empreendimentos de vendedores ambulantes, em que 3 entrevistados afirmaram que souberam da atividade de vendedor ambulante por meio de alguém de sua rede de contatos.

Como apontado por Sarasvathy (2001a; 2001b), os empreendedores iniciam seus empreendimentos a partir dos recursos disponíveis, ou seja, "Quem eles são?”, “O que eles conhecem?" e "Quem eles conhecem?”. Cabe destaque para o recurso “Quem eles conhecem?”, evidenciado pela realização de parcerias dos vendedores ambulantes. 
As alianças estratégicas apontadas por Sarasvathy (2001a; 2001b) como fator fundamental para a criação de empreendimentos foram evidenciadas pela realização de parcerias, estimulando a cooperação entre os vendedores ambulantes e stakeholders, elemento que contribui para eliminar e reduzir incertezas e construir barreiras que reduzam a competição dessa atividade comercial turística.

Os fornecedores da maioria dos informantes (5) são do município de Pontal do Paraná. A aquisição de produtos para comercialização pelos vendedores ambulantes em Pontal do Paraná contribui para o giro de capital financeiro no município e para o crescimento de empreendimentos formais locais.

Três dos informantes iniciaram as atividades como vendedor ambulante em 2015. Os outros 3 entrevistados iniciaram suas atividades em 1997, 1999 e 2003. Dois dos informantes entrevistados indicaram que não tinham nenhuma informação ou conhecimento sobre a atividade de vendedor ambulante em Pontal do Paraná.

Os motivos que levaram os empreendedores a desenvolverem atividades como vendedores ambulantes diferiram. Dois informantes indicaram empreender por necessidade de obtenção de uma renda e os outros quatro por complementação de renda. Em 1 dos empreendedores fica evidente o empreendedorismo por oportunidade, ou de transformação do que seria uma necessidade em oportunidade, pois o empreendedor informou possuir 11 carrinhos e também auxiliar pessoas a iniciarem suas atividades como vendedores ambulantes, recebendo uma porcentagem do lucro das vendas como forma de pagamento.

Referente à escolha dos produtos para comercialização, os entrevistados indicaram que o principal critério é a praticidade de manipulação do produto no momento da entrega ao cliente/ consumidor na praia.

O período em que os informantes desenvolvem atividades se constitui, principalmente, no período de temporada de verão, feriados e alguns finais de semana quando há fluxo de visitantes e turistas no município.

Quanto ao investimento inicial, são provenientes de recursos próprios, cuja recuperação ocorreu na primeira temporada de atividade. Dentre os entrevistados, um deles realiza controle financeiro e os demais apresentam noções de seus gastos e lucros com a atividade.

As principais dificuldades enfrentadas pelos vendedores ambulantes apontadas pelos entrevistados durante a atividade são: “o calor e exposição solar", "colocar e tirar o carrinho da praia devido ao seu peso", "troco em dinheiro", "aprender a usar o carrinho" e "transporte dos produtos devido ao peso". 
As principais reclamações dos turistas quanto aos produtos comercializados pelos vendedores ambulantes, conforme os entrevistados, referem-se à qualidade dos produtos e ao preço, considerado como alto.

Quanto ao futuro da atividade dos vendedores ambulantes no município, os entrevistados relataram receio que a atividade deixe de existir devido à implantação de quiosques na praia, o que implicaria, segundo estes, em desemprego para muitos vendedores ambulantes que não teriam condições financeiras para adquirir um quiosque. Essa constatação vai ao encontro do que aponta Sarasvathy $(2001 \mathrm{a} ; 2001 \mathrm{~b})$ na abordagem Effectuation, de que é preferível controlar um futuro imprevisível ao invés de prever um futuro incerto.

Segundo a Prefeitura Municipal de Pontal do Paraná, há um projeto no município para a implantação dos quiosques, mas sua aprovação só seria possível após a aprovação do Plano Diretor do Município. O referido Plano Diretor foi aprovado em janeiro de 2017, data posterior à realização da pesquisa. Conforme o Departamento Municipal de Vigilância Sanitária e Epidemiológica, a implantação de quiosques seria positiva no que se refere à higiene e saúde, principalmente para os produtos oferecidos na praia que precisam de manipulação no momento de entrega aos turistas, como os alimentos, que precisam ser mantidos refrigerados ou serem aquecidos. Com relação às bebidas e os alimentos que não precisam de manipulação, a exemplo de sorvetes, não há necessidade de quiosques, o que viabilizaria a continuidade de comercialização por parte dos vendedores ambulantes. Cabe citar que no ano vigente, 2019, não foi observada a implantação de quiosques na praia de Pontal do Paraná e as vagas para o comércio ambulante continuam sendo oferecidas no município.

Referente às perspectivas quanto ao progresso profissional dos vendedores ambulantes entrevistados identificou-se uma lacuna, o que nos remete à reflexão de Soares (2008) sobre o fato do setor informal não apresentar elementos que lhe permitem crescimento sustentado. Por outro lado, cabe citar que os respondentes do questionário socioeconômico indicaram, em sua maioria, que adquirem os produtos para comercialização como vendedores ambulantes, em estabelecimentos de Pontal do Paraná.

Assim, se de um lado a atividade dos vendedores ambulantes, sendo informal, não apresenta possibilidade de crescimento, por outro, contribui com o crescimento de empreendimentos do próprio município, estimulando fluxo de capital financeiro local. 


\section{Considerações Finais}

Este artigo comunicou resultados de uma investigação motivada pelo desejo de compreensão das peculiaridades de Pontal do Paraná, no âmbito do turismo e do empreendedorismo, notadamente relacionados ao setor informal e comércio ambulante. $\mathrm{O}$ empreendedorismo informal nesse município é decorrente da sazonalidade, originária do turismo de sol e praia, uma das principais atividades econômicas do município. O aumento do fluxo de visitantes no período de temporada de verão impulsiona a criação desses empreendimentos informais que operam no comércio cotidiano, ao lado de empreendimentos formais.

Vale reiterar a expressividade da atividade comercial turística dos vendedores ambulantes para a economia do município, pois esta compreende aproximadamente $2,5 \%$ da população do município de Pontal do Paraná, conforme o IBGE (2016). Por extensão, reafirma-se a importância do turismo de sol e praia para a economia do município, como já indicada por Sampaio (2006a; 2006b) e IBGE (2016).

O estudo de caso como método escolhido para efetivar a investigação mostrou-se adequado, pois o conjunto de dados recolhidos e analisados possibilitou o atingimento dos objetivos traçados. Foram coletados dados qualitativos referentes às formas de organização da atividade comercial turística, aos aspectos do processo de criação de empreendimentos informais dos vendedores ambulantes, a partir de pesquisa documental e entrevistas, e às características de perfil socioeconômico e perfil empreendedor, utilizando questionários.

A atividade comercial turística dos vendedores ambulantes de Pontal do Paraná está organizada por duas instituições: AVAPAR e Prefeitura Municipal e acontece paralelamente ao setor formal, como parte da dinâmica econômica desse município, ou seja, como parte do sistema capitalista, tomando um espaço não ocupado pelo setor formal (CACCIAMALI, 1983; SOARES, 2008).

Se por um lado a atividade dos vendedores ambulantes, por ser informal, não apresenta possibilidades de expansão, por outro, por ser realizada em paralelo ao setor formal e considerando que os respondentes do questionário socioeconômico apontaram que adquirem seus produtos no município onde residem e desenvolvem as atividades como vendedores ambulantes, tal atividade apresenta contribuição para o crescimento dos empreendimentos formais locais, visto que essa ação faz com que o capital financeiro resultante da atividade permaneça no município.

Considerando as peculiaridades da atividade comercial turística dos vendedores ambulantes, a qual está inserida no município de Pontal do Paraná desde antes de sua emancipação 
de Paranaguá, é inadequado generalizar quanto à possibilidade de formalização ou não, visto que a formalização pode gerar vantagens para os empreendedores por oportunidade enquanto que para os empreendedores por necessidade pode gerar uma limitação quanto ao desenvolvimento de apenas uma atividade como fonte de renda. Para os empreendedores por necessidade, considera-se como mais adequado orientá-los quanto à contribuição para a Previdência Social de maneira autônoma, a qual garantiria a eles os benefícios de um trabalhador assalariado.

Observa-se a ausência de preocupação quanto à atividade comercial turística dos vendedores ambulantes no que se refere ao cuidado ambiental, como por exemplo os impactos gerados por essa atividade nas praias do município e o descarte de resíduos oriundos da atividade dos vendedores ambulantes. Observa-se, ainda, que apesar de instituições ambientalistas estarem instaladas no município, não possuem relação alguma com a referida atividade comercial.

Espera-se que esse estudo se torne um estímulo para outros pesquisadores investigarem sobre a atividade comercial turística dos vendedores ambulantes no litoral do Paraná sob diferentes abordagens, como econômica, ambiental, geográfica, administrativa, política e interdisciplinar, possibilitando uma visão sistêmica e complexa do tema.

\section{Referências}

BARDIN, L. Análise de Conteúdo. 4. ed. Lisboa: Edições 70, 2010.

BARTEL, G. Análise da Evolução das Características Comportamentais Empreendedoras dos Acadêmicos do Curso de Administração de uma IES Catarinense. 2010. 107 p. Dissertação (Mestrado em Administração) - Programa de Pós-graduação em Administração, Universidade Regional de Blumenau, Blumenau.

CACCIAMALI, M. C. Setor Informal Urbano e Formas de Participação na Produção. São Paulo: Instituto de Pesquisas Econômicas da Faculdade de Economia e Administração da Universidade de São Paulo, 1983.

CACCIAMALI, M. C. Globalização e processo de informalidade. Economia e Sociedade, Campinas, v. 14, p. 153-174, jun. 2000.

CASTELLI, G. Turismo e marketing: uma abordagem hoteleira. Porto Alegre: Sulina, 1986.

CRESWELl, J. W. Projeto de Pesquisa: Métodos Qualitativo, Quantitativo e Misto. 3. ed. Porto Alegre: Artmed, 2010.

CRUZ, C. A. B. O desenvolvimento do mercado informal como elemento de geração de novos empreendedores. Revista Científica do ITPAC, Araguaína, v. 7, n. 4, Pub. 1, out. 2014. 
DEDECCA, C. S. Setor informal e informalidade no Brasil. Ciência Hoje, v. 39, jan./fev. 2007.

GLOBAL ENTREPRENEURSHIP MONITOR (GEM). Empreendedorismo na Região Sul do Brasil. IBQP/ SEBRAE/ IEL, 2013.

GIL, A. C. Como elaborar projetos de pesquisa. 4. ed. São Paulo: Atlas, 2002.

HISRICH, R. D.; PETERS, M. P. Empreendedorismo. 5. ed. Porto Alegre: Bookman, 2004.

INSTITUTO BRASILEIRO DE GEOGRAFIA E ESTATÍSTICA (IBGE). IBGE Cidades. Disponível em: https://cidades.ibge.gov.br/. Acesso: diversos em 2019.

INSTITUTO PARANAENSE DE DESENVOLVIMENTO ECONÔMICO E SOCIAL (IPARDES). Tipologias dos municípios paranaenses: segundo indicadores socioeconômicos e demográficos. Curitiba: IPARDES, 2010.

INSTITUTO PARANAENSE DE DESENVOLVIMENTO ECONÔMICO E SOCIAL (IPARDES). Base de dados do Estado (BDE). Curitiba: 2011. Disponível em: http://www.ipardes.gov.br/. Acesso: diversos em 2019.

LAVILle, C.; DIONNE, J. A Construção do Saber: Manual de Metodologia da pesquisa em ciências humanas. Porto Alegre: Artmed; Belo Horizonte: Editora UFMG, 1999.

LOHMANN, G.; PANOSSO NETTO, A. Teoria do Turismo: conceitos, modelos e sistemas. 2. ed. São Paulo: Aleph, 2012.

MACHADO DA SILVA, L. A. Mercados metropolitanos de trabalho manual e marginalidade. 1971. Dissertação (Mestrado em Antropologia Social) - Programa de Pós-Graduação em Antropologia Social do Museu Nacional, Universidade Federal do Rio de Janeiro, Rio de Janeiro.

MOTA, K. C. N. Marketing Turístico: promovendo uma atividade sazonal. São Paulo: Atlas, 2001.

NORONHA, E. G. "Informal”, ilegal, injusto: percepções do mercado de trabalho no Brasil. RBCS - Revista Brasileira de Ciências Sociais, v. 18, n. 53, p.111-129, out. 2003

PELOGIO, E. A.; ROCHA, L. C. S.; MACHADO, H. V.; AÑEZ, M. E. M. Criação de Empresas à Luz do Modelo de Decisão Effectuation: um estudo com Mulheres Empreendedoras no Município de Currais Novos/RN. XXXV EnANPAD. Rio de Janeiro/RJ - 4 a 7 de setembro de 2011.

PIERRI, N. E. O litoral do Paraná: entre a riqueza natural e a pobreza social. Usos e conflitos. Desenvolvimento e Meio Ambiente, Curitiba, n. 8. p. 25-41, jul./dez. 2003.

PIERRI, N. E. et al. A ocupação e o uso do solo no litoral paranaense: condicionantes, conflitos e tendências. Desenvolvimento e Meio Ambiente, Curitiba, Editora UFPR, n. 13, p. 137-167, jan./jun. 2006. 
PONTAL DO PARANÁ. Lei $\mathbf{n}^{\mathbf{0}} \mathbf{6 2 1}$, de novembro de 2005. Dispõe sobre o exercício de comércio ambulante e de comércio ou prestação de serviço eventual, no município de Pontal do Paraná, durante o período considerado "temporada de verão". 2005. Disponível em: https://leismunicipais.com.br/a/pr/p/pontal-do-parana/lei-ordinaria/2005/62/621/lei-ordinaria-n-6212005-dispoe-sobre-o-exercicio-de-comercio-ambulante-e-de-comercio-ou-prestacao-de-servicoeventual-no-municipio-de-pontal-do-parana-durante-o-periodo-considerado-temporada-de-verao. Acesso em: vários de 2015 a 2019.

SAMPAIO, R. Ocupação das orlas das praias paranaenses pelo uso balneário. Desenvolvimento e Meio Ambiente, Curitiba, Editora da UFPR, n. 13, p. 169-186, jan./jun. 2006.

SAMPAIO, R. Ocupação das orlas das praias paranaenses pelo uso balneário. Curitiba, 2006. Tese. (Curso de Doutorado em Meio Ambiente e Desenvolvimento, da Universidade Federal do Paraná).

SARASVATHY, S. Causation and effectuation: towards a theoretical shift from economic inevitability to entrepreneurial contingency. Academy of Management Review, v. 26, p. 243-288, 2001.

SARASVATHY, S. Effectual reasoning in entrepreneurial decision making: existence and bounds. Best paper proceedings. Academy of Management, Washington, p. 3-8, 2001.

SILVA, J. L. T. A face informal dos serviços: o caso do comércio ambulante no Rio de Janeiro, 1999. Dissertação (Curso de Mestrado em Economia da Faculdade de Economia da Universidade Federal Fluminense).

SOARES, M. A. T. Trabalho informal: da funcionalidade à subsunção ao capital. Vitória da Conquista: UESB, 2008.

SULZBACH, M. T; DENARDIN, V. F; FELISBINO, J. N. O trabalho em pequenos municípios praianos no litoral do Paraná. Revista Sociologias Plurais, n. especial 1, p. 108-132, out. 2012.

VIEIRA, R. S. Empreendedorismo Informal em Balneários Marítimos: o caso da atividade comercial turística dos vendedores ambulantes de Pontal do Paraná - Paraná - Brasil. 2016. 179 p. Dissertação (Mestrado em Turismo) - Programa de Pós-graduação em Turismo, Universidade Federal do Paraná, Curitiba.

YIN, R. K. Estudo de Caso: Planejamento e Métodos. 4. Ed. Porto Alegre: Bookman, 2010.

Artigo recebido em 13/05/2019. Aceito para publicação em 04/10/2019. 